\title{
Chemokine Modulation Therapy
}

National Cancer Institute

\section{Source}

National Cancer Institute. Chemokine Modulation Therapy. NCI Thesaurus. Code C153205.

Therapy used to modulate the activity of chemokine receptors or their ligands, potentially modifying immune response and tumor-related processes, including tumor cell growth, angiogenesis, and metastasis. 